\title{
AN ETHNOBOTANICAL SURVEY ON PLANTS OF VETERINARY IMPORTANCE IN TWO WOREDAS OF SOUTHERN TIGRAY, NORTHERN ETHIOPIA
}

\author{
Mirutse Giday and Gobena Ameni \\ Institute of Pathobiology, Addis Ababa University, PO Box 1176 \\ Addis Ababa, Ethiopia. E-mail: mirutseg@hotmail.com
}

\begin{abstract}
The purpose of the survey was to document and analyze information on the traditional use of medicinal plants by farmers in Ofla and Raya-Azebo woredas of South Tigray Zone for the treatment and prevention of livestock ailments. Data were collected mainly through interviews carried out with randomly selected farmers of the two woredas. During the survey, 83 medicinal plant species were reported as being used for the treatment of 37 types of livestock ailments. A high proportion of the species $(17 \%)$ were claimed to have been used as remedies for wound infections. The highest informant consensus was recorded for the plant Achyranthes aspera L. where 18 out of the total informants $(9 \%)$ reported the use of the species as remedy against inflammation of the eye in cattle. Leaves are the most commonly sought plant parts in remedy preparations. Most of the remedies $(96 \%)$ are prepared from freshly collected plant parts and a higher proportion being administered orally. The majority of the plants were found to be harvested from the wild. A significant difference $(p<0.05)$ was observed between the average numbers of medicinal plants that were reported by farmers of the two woredas; on average two plant species were reported by the farmers from Raya-Azebo, whereas, only one plant species was reported by the farmers from Ofla. Further studies are needed to evaluate the efficacies and possible side effects of the traditional medicinal plants before they are recommend for their wider use both in the study area and elsewhere in the country.
\end{abstract}

Key words/phrases: Ethiopia, ethnobotany, ethnoveterinary, medicinal plants, Southern Tigray

\section{INTRODUCTION}

Ethiopia is one of the leading countries of Africa in livestock population. According to the Ethiopian Agricultural Research Organization (EARO) (1999), the country has about 31 million heads of cattle, 27 million sheep, 24 million goats, 7.02 million equine, 1 million camels and 56 million poultry. Livestock production is an integral part of the Ethiopian agriculture and shares about $40 \%$ of the total agricultural output (EARO, 1999).

Although Ethiopia is rich in its livestock population, it is one of the countries in the world with the lowest unit output. The poor health condition of its livestock has partially been responsible for the low productivity. Tsetse borne trypanosomiasis, contagious bovine pleuropneumonia, rinderpest and foot-and-mouth disease are among the major health problems of livestock (EARO, 1999). Modern livestock health care is still at its lowest stage in the country due to lack of adequate clinics, veterinarians and supply of drugs. Besides, most modern drugs are expensive and, as a result, not affordable by the majority of Ethiopian farmers and pastoralists. Most of the Ethiopian farmers and pastoralists, therefore, rely on their traditional knowledge, practices and locally available materials (mainly plants) in the control of diseases of their domestic animals.

However, such rich ethnoveterinary knowledge, which has been transferred verbally from one generation to the next from time immemorial, is currently in danger of being lost. Medicinal plants, which have been used in ethnoveterinary practices, are being depleted at an alarming rate because of the continued environmental degradation in Ethiopia as a result of deforestation, overgrazing and recurrent drought as well as overexploitation and destructive harvesting of the medicinal plants themselves. Unless such medicinal plants are locally available in a reasonable amount, it becomes difficult to continue the practice. This in turn could pave a way to the deterioration or complete loss of the knowledge. Loss of knowledge has been aggravated by the expansion of modern education, which has made the younger generation underestimate its traditional values.

To our dismay, very little effort has so far been made to reverse or stop the trend. Few ethnoveterinary surveys (Lidetu Alemu, 1993; Yihenew Mekonnen, 1994; Ayalew Tolosa, 1997; Gemechu Wirtu et al., 1999; Mirutse Giday, 1999) have been conducted in the country to document the medicinal plants used and the associated ethno- 
veterinary knowledge. Enormous knowledge is still being lost before it is recognized and properly documented, and medicinal plants go extinct before appropriate conservation measures are taken. Thus, there is an urgent need for a documentation of the knowledge in the country and conservation of the medicinal plants, which have been used in the practice, but are currently on the verge of extinction. By reducing the loss of the medicinal plants used and the associated knowledge through conservation measures and documentation, respectively, the continuation of the ethnoveterinary practice could be guaranteed. Besides, such ethnoveterinary knowledge could serve as a lead in the development of modern herbal drugs.

Like the farmers/pastoralists, elsewhere, in the country, most of the farmers in Southern Tigray are to a large extent dependent on their ethnoveterinary knowledge and practices, which mainly involve the use of locally available medicinal plants. Such knowledge and practices are, however, currently under threat mainly because of the depletion of the locally available medicinal plants as a result of the large-scale environmental degradation and recurrent drought that have been taking place in their worst form, in this part of the country. Very little effort has so far been made to record and document the medicinal plants used and the associated knowledge. Immediate measures should, therefore, be taken to rescue the plants and the associated knowledge from further loss. But before such measures are taken, the extent of the knowledge of the ethnoveterinary practice involving medicinal plants should be investigated properly through ethnobotanical surveys.

The aim of this survey was, therefore, to document and analyze the existing ethnoveterinary knowledge and practices of farmers associated with the use of medicinal plants in two woredas (districts) of South Tigray Zone.

\section{THE STUDY AREA}

South Tigray is one of the four administrative zones of the Tigray Regional Administration. It is divided into eight administrative woredas. The area is well known for its high livestock population. Cattle, sheep, chicken, goats, equine and camels are the domestic animals commonly raised in the area. A survey conducted in 2001/02 showed that
South Tigray Zone has 631,186 heads of cattle (Central Agricultural Census Commission, 2003).

For the ethnoveterinary survey, two woredas of the South Tigray Administrative Zone were selected, namely the Ofla and Raya-Azebo woredas (Fig. 1). These woredas are found at close distances from the historic town of Maichew. Maichew is located at $662 \mathrm{kms}$ north of Addis Ababa. In terms of the ethnoveterinary and other farming practices of the people, as well as livestock composition, the two woredas are believed to represent most areas of Southern Tigray: Ofla Woreda representing the western highland areas, and Raya-Azebo Woreda representing the eastern lowland areas.

\section{Ofla}

The altitudes of the areas surveyed in the woreda range between 2400 to 2450 meters a.s.l. Euphorbia abysssinica and Becium grandiflorum are among the dominant plant species naturally growing in the area. Tef, barley and maize are the commonly cultivated field crops.

Of all the domestic animals raised in the woreda, cattle population takes the lead, claimed to be 72,924 heads, followed by chicken $(97,248)$ and sheep (49,772) (Central Agricultural Census Commission, 2003). Blackleg, pasteurellosis, anthrax, fascioliasis and trypanosomiasis are among the diseases occurring in the area (unpublished data, Ofla Woreda Agricultural Office). Three veterinary clinics are available in the woreda.

\section{Raya-Azebo}

The altitudes of the surveyed area in the woreda ranges between 1600 and 1830 meters a.s.l. Euphorbia abysssinica and Opuntia ficus-indica are among the frequently occurring species in the specific sites of the woreda covered by the ethnobotanical survey. Sorghum and maize are the widely cultivated field crops.

Similar to Ofla woreda, cattle $(139,127)$, chicken $(100,079)$ and goats $(16,969)$ take the highest number of the livestock population in Raya-Azebo (Central Agricultural Census Commission, 2003). Sheep pox, contagious caprine pleuropneumonia (ССР), lumpy skin disease, babesiosis, trypanosomiasis and streptotrichosis are among the prevalent diseases in the area (unpublished data, Raya-Azebo Woreda Agricultural Office). Five veterinary clinics are operational in the woreda. 


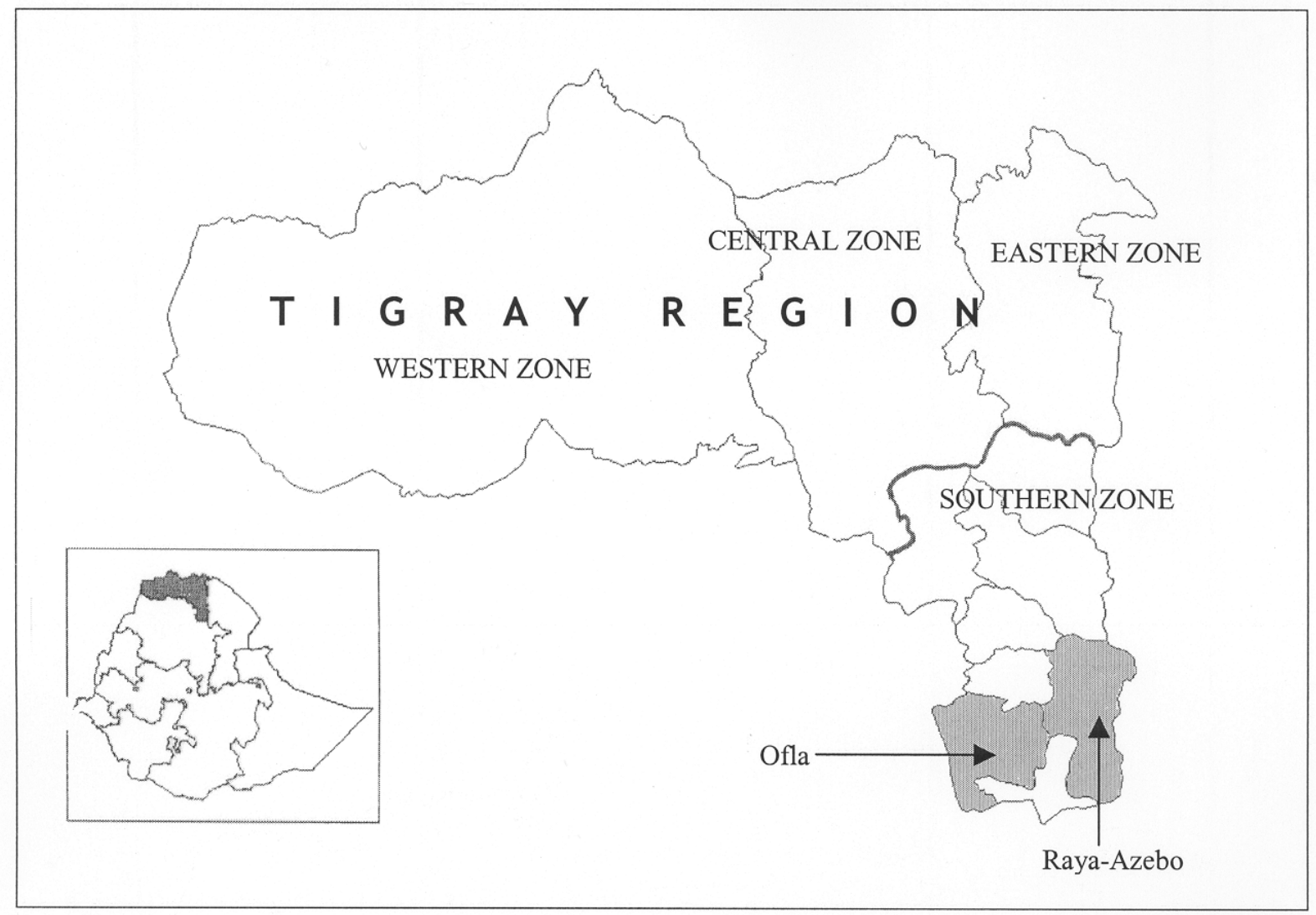

Fig. 1. Map of the study area; arrows show the surveyed woredas. [Modified from UNDP-EUE (1996).]

\section{MATERIALS AND METHODS}

\section{Survey sites}

For the ethnoveterinary survey, three villages were chosen from each of the selected woredas. They are Adi-Golo, Menkere and Hashenge from Ofla Woreda, and Tsegea, Ebo and Mechara from RayaAzebo Woreda. The villages were chosen because of their easy accessibility.

\section{Informants}

For the survey, 202 farmers (194 males and 8 females), 146 from Ofla and 56 from Raya-Azebo, volunteered to serve as informants. The age of the informants ranged from 18 to 92 . They were picked up during transect walks made to the selected villages of the two woredas. Initially, there was a plan to interview a comparable number of informants from Raya-Azebo woreda. This was, however, not achieved as farmers were busy in different farming activities during the time where most of the interviews were conducted. Although more females than the number stated above were encountered during the visits, only few of them were willing to sit for the interview. It was learned that there were no specialized livestock healers in the study area.

\section{Methods of data collection and analysis}

Ethnoveterinary data were collected during two trips made to the survey areas in October 2001 and April 2002. These are the months where most of the seasonal herbs are found blooming. The data were collected mainly through separate interviews and discussions held with the selected informants. For this purpose, a semi-structured questionnaire was prepared before hand. The interviews were conducted in Tigrigna, a widely spoken language in the area. During the interview, data regarding 
the kinds of ailments treated and the types of medicinal plants used (including their local names) in the day-to-day ethnoveterinary practices of the people in the area, the plant parts used, remedy preparations, route of administration and dosage were collected. Besides, information on marketability and cultivation practices of the medicinal plants was gathered. Veterinarians serving in the study area played a major role in translating the local disease names into their English equivalents. Herbarium specimens for most of the reported medicinal plants were gathered, properly identified and vouchers were deposited at the National Herbarium of the Addis Ababa University.

The data were summarized in a way to show the most commonly sought plant part/s (root, stem, leaf, etc.), the widely used solvents or diluents in remedy preparation and the frequently employed mode of administration. Data were also analyzed in order to understand the degree of local trade and habit of cultivation of medicinal plants by the farmers in the area. Knowledge of medicinal plants between farmers residing in the two woredas was also compared using Stata Version 6 software, and statistical significance was determined by employing the Student t-test at 95\% confidence intervals.

The relative importance of each reported medicinal plant was assessed based on the proportion of informants who independently reported its use as a remedy against a particular disease/disease category following an approach used by Trotter and Logan (1986). Such agreement of informants is usually referred to as informants consensus.

\section{RESULTS}

\section{The medicinal plants and their applications}

During the survey, a total of 83 plant species (44 from Ofla and 60 from Raya-Azebo) that belong to 50 families and 75 genera were reported to have been used as treatments against 37 types of livestock ailments in the study area (Annex 1). Of the total, 21 species were found to have simultaneously been used in both woredas for the same or different veterinary purposes. The family
Fabaceae took a bigger proportion of the reported medicinal plants accounting for $12 \%$, followed by Solanaceae $(7 \%)$ and Lamiaceae $(6 \%)$. Of the total reported species, $45.8 \%$ are herbs, $27.7 \%$ are shrubs and $26.5 \%$ are trees.

Most of the claimed medicinal plants (90\%) were found to have been used as remedies against 23 types of cattle ailments, nearly two-third of the total livestock diseases reported by the informants (Table 1). A high proportion of species were claimed to have been used as remedies for the treatments of wound infections accounting for $17 \%$ of the total medicinal plants reported, followed by leech infestation (16\%), strangles (15\%), inflammation of the eye (14\%) and anthrax (11\%). Some of the claimed medicinal plants are used as treatments against several types of livestock ailments. The plants, Solanum incanum and Euphorbia abyssinica, for example, are used for the treatment of seven and five kinds of livestock ailment, respectively.

Table 1. Proportions of medicinal plants used in the treatments of the ailments of the different livestock types.

\begin{tabular}{lcc}
\hline $\begin{array}{l}\text { Type of } \\
\text { livestock }\end{array}$ & $\begin{array}{l}\text { No. of species } \\
\text { reported }(\%)\end{array}$ & $\begin{array}{c}\text { No. of ailments } \\
\text { treated }\end{array}$ \\
\hline Cattle & $75(90 \%)$ & 23 \\
Equine & $40(48 \%)$ & 7 \\
Sheep & $24(29 \%)$ & 6 \\
Goat & $24(29 \%)$ & 6 \\
Camel & $17(20 \%)$ & 3 \\
Chicken & $3(4 \%)$ & 2 \\
\hline
\end{tabular}

Some of the reported medicinal plants in the study area were found to be popular among the farmers with relatively higher informants consensus for being used as remedies against particular type of diseases (Table 2). A highest agreement of informants was recorded for Achyranthes aspera L. Eighteen out of the total 202 informants (9\%) reported the use of A. aspera as a remedy against inflammation of the eye in cattle. The species, Nicotiana tabacum L., Impatiens rothii and Aloe sp. also scored higher informant consensus for being used as treatments against leech infestation $(6.4 \%)$, lungworm pneumonia $(5.4 \%)$ and bloat $(4.5 \%)$, respectively. 
Table 2. List of medicinal plants reported as remedies against particular types of disease by five or more informants.

\begin{tabular}{llll}
\hline Scientific name & Local name & Type of ailment treated & $\begin{array}{l}\text { No. of } \\
\text { informant }\end{array}$ \\
\hline Achyranthes Aspera & mechelo, gurbe & inflammation of the eye (cattle) & $18(9 \%)$ \\
Nicotiana tabacum & timbaho & leech infestation (cattle) & $13(6.4 \%)$ \\
Impatiens rothii & gurshit & lungworm pneumonia (cattle) & $11(5.4 \%)$ \\
Aloe sp. & ble & bloat (cattle) & $9(4.5 \%)$ \\
Calpurnia aurea & hitsawts, cherecnchah & mange mites (cattle, sheep, goat and & $7(3.5 \%)$ \\
& & equine) & $6(3 \%)$ \\
Ricinus communis & lice infestation (chickens) & $6(3 \%)$ \\
Meriandra bengalensis & mesaguh & external wound infection (cattle) & $5(2.5 \%)$ \\
& & lung worm pneumonia (cattle, goat, & \\
Rumex nervosus & sheep) & $5(2.5 \%)$ \\
Silene macrosolen & strangles & $5(2.5 \%)$ \\
Senecio myriocephalus & strangles & $5(2.5 \%)$ \\
\hline
\end{tabular}

Plant parts used, preparation and route of administration

Leaves and roots are the most commonly used plant parts in the preparation of remedies accounting for $70 \%$ and $35 \%$ of the total medicinal plants, respectively, followed by seeds and fruits (16\%).

The majority of the remedies (96\%) are prepared from freshly collected plants in the form of juice or paste. It was revealed that about $79 \%$ of the remedies are prepared without the use of solvents or diluents. When solvents are needed, however, it is water that is frequently used. Human saliva and urine as well as milk and butter are also used as solvents or additives, to some degree, in the preparation of remedies.

Preparations of nearly half $(45 \%)$ of the total reported plant remedies are given orally. Remedies of a big number of plants are also frequently applied topically on the skin and given nasally accounting for $36 \%$ and $32 \%$ of the total reported species, respectively. For most of the diseases reported, remedies are continuously given on daily basis until a significant improvement in health conditions are noticed. Lack of consistency among the informants on the levels of daily doses for many of the remedies was frequently noted.

\section{Comparison of the medicinal plants knowledge between farmers of the two woredas}

About $70 \%$ of the farmers interviewed from the two woredas reported the knowledge of at least one medicinal plant; and the average number of reported medicinal plants by the same informants was between one and two.

A significant difference $(\mathrm{p}<0.05)$ was observed between the average numbers of medicinal plants that were reported by farmers of the two woredas; on average, two plant species were reported by the farmers from Raya-Azebo, whereas, only one species was reported by the farmers from Ofla (Table 3).

Table 3. Number (\%) of informants in the two woredas in relation to the number of medicinal plants reported by each of the interviewees.

\begin{tabular}{ccc}
$\begin{array}{c}\text { No of plants } \\
\text { reported }\end{array}$ & $\begin{array}{c}\text { Ofla Woreda } \\
\mathrm{n}=146\end{array}$ & $\begin{array}{c}\text { Raya-Azebo Woreda } \\
\mathrm{n}=56\end{array}$ \\
\hline 0 & $54(36.99)$ & $7(12.50)$ \\
1 & $42(28.77)$ & $26(46.43)$ \\
2 & $26(17.81)$ & $12(21.43)$ \\
3 & $13(8.90)$ & $2(3.57)$ \\
4 & $5(3.42)$ & $3(5.36)$ \\
5 & $5(3.42)$ & $3(5.36)$ \\
$6+$ & $1(0.68)$ & $3(5.36)$ \\
\hline
\end{tabular}




\section{Local status of the reported medicinal plants}

Of the total claimed medicinal plants, more than half $(60 \%)$ were found to be growing wild, and about $15 \%$ were reported to be weeds. Around $25 \%$ of the medicinal plants were reported to have been grown in and around home gardens or in cultivation fields although most of them are primarily cultivated for other purposes. Except for the cultivated and weedy species, long distance walks are required to collect medicinal plants because of their limited occurrence. According to the informants, the wild plants Grewia villosa, Berberis holistii, Pittosporum viridiflorum, Maerua angolensis and ADEMOMIN (local name) are the most scarce medicinal plants in the area.

There was no much treat to the reported medicinal plants as a result of local trade. Some of the reported medicinal plants (eg., fruits of Opuntia ficus-indica and Ziziphus spina-christi) were sold in markets within and around the study area. They were, however, sold primarily for other purposes.

\section{DISCUSSION}

It is encouraging to find such a good number of medicinal plants ( 83 species) that are still in use for the treatment of several livestock diseases in the area despite the large-scale environmental degradation and recurrent droughts that have been taking place in that part of the country in their worst forms. The fact that more than half of the claimed medicinal plants are herbs could indicate their relatively better abundance in the area as compared to trees and shrubs.

Proportionally, a high number of plants were claimed to have been used for the treatments of wound infections, leech infestation, strangles, inflammation of the eye and anthrax. This might indicate the economic importance of such ailments in the area. Infection by internal parasites and anthrax were reported as two of the most economically important livestock diseases in Southern Tigray (unpublished data, Southern Tigray Zone Agricultural Office).

As compared to results of a similar study that was carried out elsewhere in the country (Mirutse Giday, 1999), informants consensus values obtained for the medicinal plants that were reported during this survey were found to be low.
One of this could probably be due to the little practice by farmers in the study area to share traditional medicinal knowledge among themselves. But results of the consensus could still be useful in proritizing plants for further studies. According to Trotter and Logan (1986), pharmacologically effective remedies are expected to have relatively greater informant consensus. Accordingly, the plants Achyranthes aspera, Nicotiana tabacum, Impatiens rothii and Aloe sp. that were found as having relatively higher informants consensus for being used as remedies against inflammation of the eye, leech infestation, lungworm pneumonia and bloat, respectively are the ones that deserve further investigation. Previous phytochemical studies showed that the leaves of $A$. aspera contain active substances such as saponin, alkaloid and sterol (Dawit Abebe and Estifanos Hagos, 1991).

Thirty-three percent of the plant remedies that were cited during this survey were also reported by different authors to have been used medicinally elsewhere in the country (Ayalew Tolosa, 1997; Gemechu Wirtu et al., 1999; Mirutse Giday, 1999) and/or in other parts of the world (Karehed and Odhult, 1997; Dwivedi, 1999; Rangnekar, 1999; Rathore et al., 1999; Sikarwar, 1999). Even some of the plants that were reported by the farmers in the study area (e.g., Aloe sp., Calotropis procera, Cucurbita pepo, Eucalyptus globulus, Impatiens rothii, Linum usitatissimum and Nicotiana tabacum) are used exactly for the same purpose elsewhere (Ayalew Tolosa, 1997; Gemechu Wirtu et al., 1999; Mirutse Giday, 1999; Rangnekar, 1999). The fact that some of the reported plants are having similar uses elsewhere might also reveal their pharmacological effectiveness.

Analysis of the data showed that leaf is the most sought plant part in the preparation of the remedies in the area. As compared to other plant parts, e.g., underground part, stem, bark, or whole plant, harvesting leaves poses relatively less danger to the existence of an individual plant. Studies indicated that removal of up to $50 \%$ of tree leaves does not significantly affect the growth of the species studied (Poffenberger et al., 1992). The popularity of underground parts, barks and stems, however, could bring grave consequences to the survival of the medicinal plants (Dawit Abebe and Ahadu Ayehu, 1993). 
Most preparations of the reported plants in the area were found to be drawn from a single plant. In other parts of the country, however, the use of mixtures of plants in treating a particular livestock ailment is fairly common (Ayalew Tolosa, 1997; Gemechu Wirtu et al., 1999) because of the wide belief of the synergic effect of one plant on the other during the use of concoctions (Dawit Abebe and Ahadu Ayehu, 1993).

It was revealed that the farmers residing in RayaAzebo woreda, part of the lowland area of Southern Tigray, have relatively better knowledge of medicinal plants as compared to the farmers in Ofla woreda, the highland part of the study area. The better knowledge of medicinal plants of the farmers in Raya-Azebo could be attributed to the relatively better interaction they have with the neighbouring Afar people who are basically pastoralists. Pastoral people in Ethiopia who are still having very limited access to modern veterinary services are thought to have very rich ethnoveterinary knowledge (Taffese Mesfin, 2000).

The habit of cultivating plants in or around home gardens in the area for their medicinal purpose is very limited. There is also a similar trend in other parts of the country. A survey conducted by Zemede Asfaw (1997), which covered a large part of Ethiopia, showed that plants primarily cultivated in home gardens for their medicinal uses are few, accounting for only about $6 \%$ of the total species grown. There is, therefore, a high threat to the medicinal flora of the area as long as the majority of the medicinal plants are only obtained from the wild, a habitat where severe environmental degradation is still going on.

The threat from the local trade of medicinal plants in the area is very minimal. Most of the plants are harvested for local use and are only collected when the need arises. Other studies (Kloos, 1976; Kloos et al., 1978) carried out elsewhere in the country, however, indicated a wide domestic trade of medicinal plants.

Although the reported medicinal plants were claimed effective by the informants against various types of livestock diseases, this information should not be taken for granted when recommending such plants for their wider use both in the study area and elsewhere in the country. Further investigations (field and laboratory evaluations) are, therefore, needed to be done on the reported plants so as to confirm their efficacies and check possible side effects. Screening priorities should be given to those plants that scored relatively higher informants consensus in the study area and/or reported elsewhere for similar uses as such results might indicate their better efficacies. Attention should also be given to individual plants that were reported as having a wide range of ethnoveterinary uses.

In situ and ex situ conservation measures are needed to be taken for those medicinal plants, which are only found growing wild, and priorities should be given to those ones, which were reported to be found rare in the area.

\section{ACKNOWLEDGEMENTS}

First of all we would like to thank the Aklilu Lemma Foundation for its financial support to carry out this study. We are highly indebted to the Institute of Pathobiology for providing us with vechicle for our field trips. Our thanks also go to veterinarians in Southern Tigray, Dr. Gebru Legesse, Dr. Selamawit Tesfay and Mr. Yishak Hailu for their professional and administrative assistance during our visits to the study area; Mr. Girmay Medhin for his assistance in data analysis and field assistants Aselef Meresa, Babi Zekarias, Hiluf Abay and Meselle Gebre-Medhin for their help in data collection.

\section{REFERENCES}

1. Ayalew Tolosa (1997). Ethnoveterinary knowledge in central highlands of Ethiopia, Sheno, North Shoa. In: Proceedings of the $11^{\text {th }}$ Conference of the Ethiopian Veterinary Association, pp. 110-125. Addis Ababa, Ethiopia.

2. Central Agricultural Census Commission (2003). Ethiopian Agricultural Sample Enumeration, 2001/02 (1994 E.C.) Results for Tigray Region: Statistical Report on Livestock and Farm Implements. Part IV, Central Agricultural Commission, Federal Democratic Republic of Ethiopia, Addis Ababa, Ethiopia.

3. Dawit Abebe and Ahadu Ayehu (1993). Medicinal Plants and Enigmatic Health Practices of Northern Ethiopia. B.S.P.E., Addis Ababa, Ethiopia.

4. Dawit Abebe and Estifanos Hagos (1991). Plants as a primary source of drugs in the traditional health practices of Ethiopia. In: Plant Genetic resources of Ethiopia, pp 101-113, (Engles, J.M.M., 
Hawkes, J.G. and Melaku Worede, eds). Cambridge University Press, Cambridge.

5. Dwivedi, S.K. (1999). Evaluation of indigenous herbs as antitrypanosomal agents. In: Ethnoveterinary Medicine, Alternative for Livestock Development: Proceedings of an International Conference, 4-6 November 1997, pp. 108-114, (Mathias, E., Rangnekar, D.V. and McCorkle, C., eds). Pune, India.

6. EARO (1999). National Animal Health Research Programme Strategy. Ethiopian Agricultural Research Organization, Addis Ababa (EARO), Ethiopia (Draft Document).

7. Gemechu Wirtu, Girma Adugna, Temesgen Samuel, Ensermu Kelbessa and Abraham Gelato (1999). Aspects of farmers' knowledge, attitudes and practices of animal health in central Ethiopia. In: Ethnoveterinary Medicine, Alternative for Livestock Development: Proceedings of an International Conference, 4-6 November 1997, pp. 4152, (Mathias, E., Rangnekar, D.V. and McCorkle, C., eds). Pune, India.

8. Karehed, J. and Odhult, E. (1997). An Ethnobotanical Study Among the Maasai of the Loita Hills (Unpublished Report). Swedish University of Agricultural Sciences, Uppsala.

9. Kloos, H. (1976). Preliminary studies of traditional medicinal plants and plant products in Ethiopian markets. Journal of the Ethiopian Pharmaceutical Association 2:18-28.

10. Kloos, H., Assefa Tekle, Legesse Wolde-Yohannes, Ababa Yosef and Aklilu Lemma (1978). Preliminary studies of traditional medicinal plants in nineteen markets in Ethiopia: use patterns and public health aspects. Ethiopian Medical Journal 16:33-43.

11. Lidetu Alemu (1993). Studies on the Traditional Medicinal Plants of Veterinary Importance in and Around Bahir Dar (DVM thesis). Addis Ababa University, Addis Ababa.

12. Mirutse Giday (1999). An Ethnobotanical Study of Medicinal Plants Used by the Zay People in Ethiopia (MSc thesis). Swedish Biodiversity Centre, Uppsala.

13. Poffenberger, M., McGean, B., Khare, A. and Campbell, J. (1992). Community Forest Economy and Use Pattern: Participatory Rural Appraisal (PRA)
Methods in South Gujarat, India. Field Method Manual, Volume II. Society for Promotion of Wastelands Development, New Delhi.

14. Rangnekar, S. (1999). Participatory studies with women on ethnoveterinary practices for livestock health management. In: Ethnoveterinary Medicine, Alternative for Livestock Development: Proceedings of an International Conference, 4-6 November 1997, pp. 36-40 , (Mathias, E., Rangnekar, D.V. and McCorkle, C., eds). Pune, India.

15. Rathore, H.S., Rathore, S.S. and Köhler-Rollefson, I. (1999). Traditional animal health services: a case study from the Godwar area of Rajasthan. In: Ethnoveterinary Medicine, Alternative for Livestock Development: Proceedings of an International Conference, 4-6 November 1997, pp. 162-170, (Mathias, E., Rangnekar, D.V. and McCorkle, C., eds). Pune, India.

16. Sikarwar, R.L.S. (1999). Less-known ethnoveterinary uses of plants in India. In: Ethnoveterinary Medicine, Alternative for Livestock Development: Proceedings of an International Conference, 4-6 November 1997, pp. 103-107, (Mathias, E., Rangnekar, D.V. and McCorkle, C., eds). Pune, India.

17. Taffese Mesfin (2000). Ethnoveterinary practices of camel herders of Southern Afar area. Paper presented on the workshop "Indigenous Knowledge Systems of the Ethiopian People", March 4, 2000. The Ethiopian Chapter of OSSREA. Online: www.ossrea.net/nw/ethiopia/nw-02.htm.

18. Trotter, R.T. and Logan, M.H. (1986). Informants consensus: a new approach for identifying potentially effective medicinal plants. In: Plants in Indigenous Medicine and Diet, pp. 91-112, (Etkin, N.L., ed.) Redgrave Publishing Company, Bedford Hill, NY

19. Yihenew Mekonnen (1994). A survey of plants (potentially) toxic to livestock in the Ethiopian Flora. SINET: Ethiop. J. Sci. 17:9-32.

20. Zemede Asfaw (1997). Survey of indigenous food plants, their preparations and home gardens in Ethiopia. In: Indigenous African Food Crops and Useful Plants (Bede N. Okigbo, B.N., ed.) UNU/INRA Assessment Series. No. B6. 


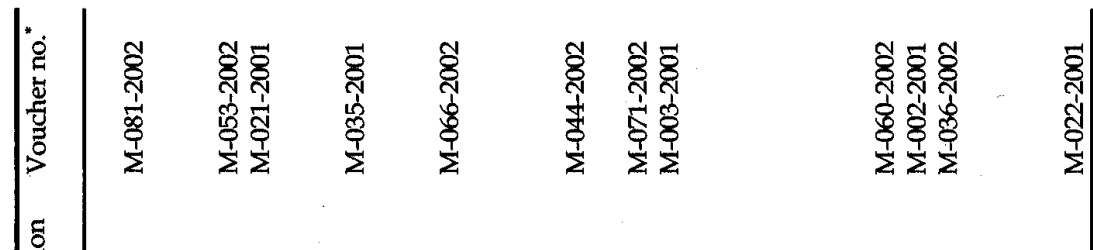
政1

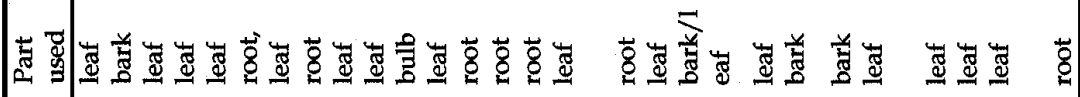

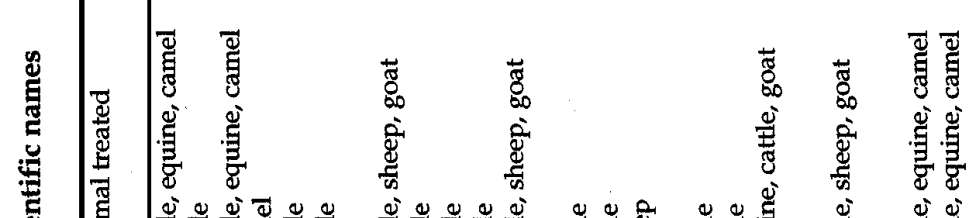

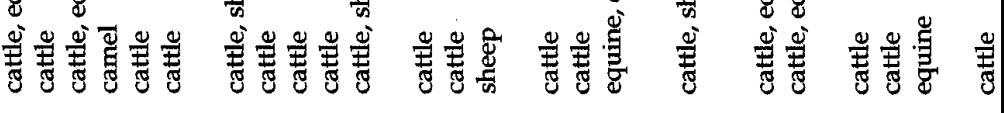

\section{总}

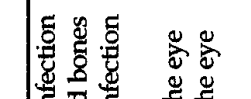

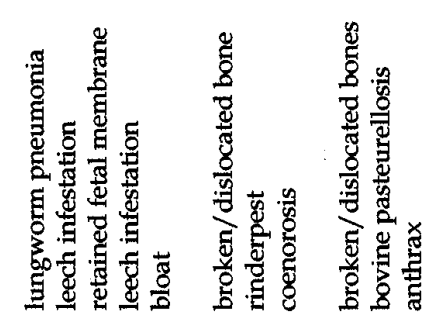

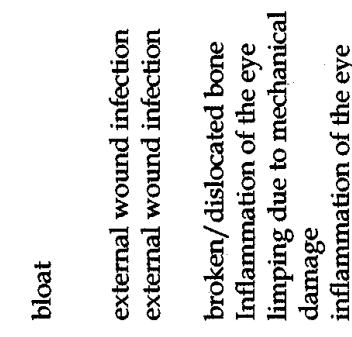

\section{直}

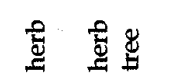

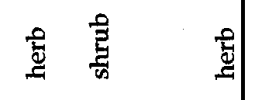

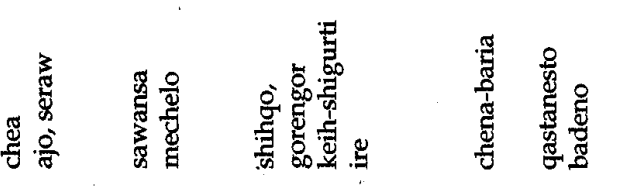

竞竞

$\sqrt{1}$

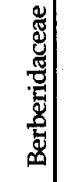

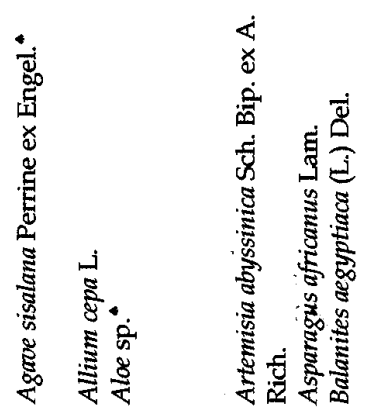

荡

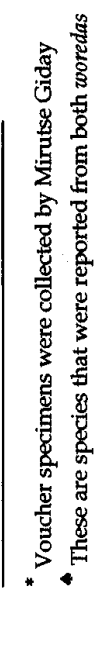




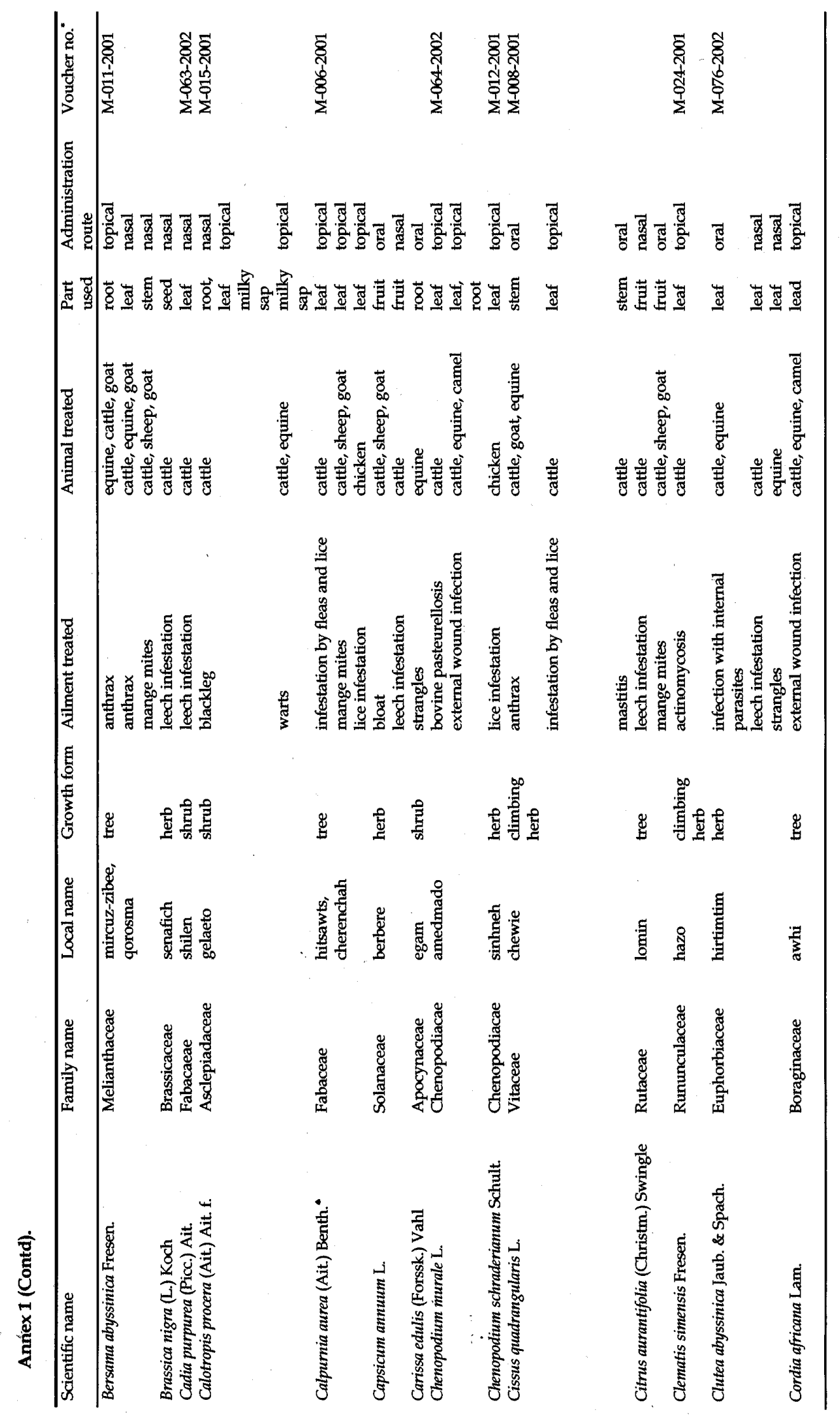




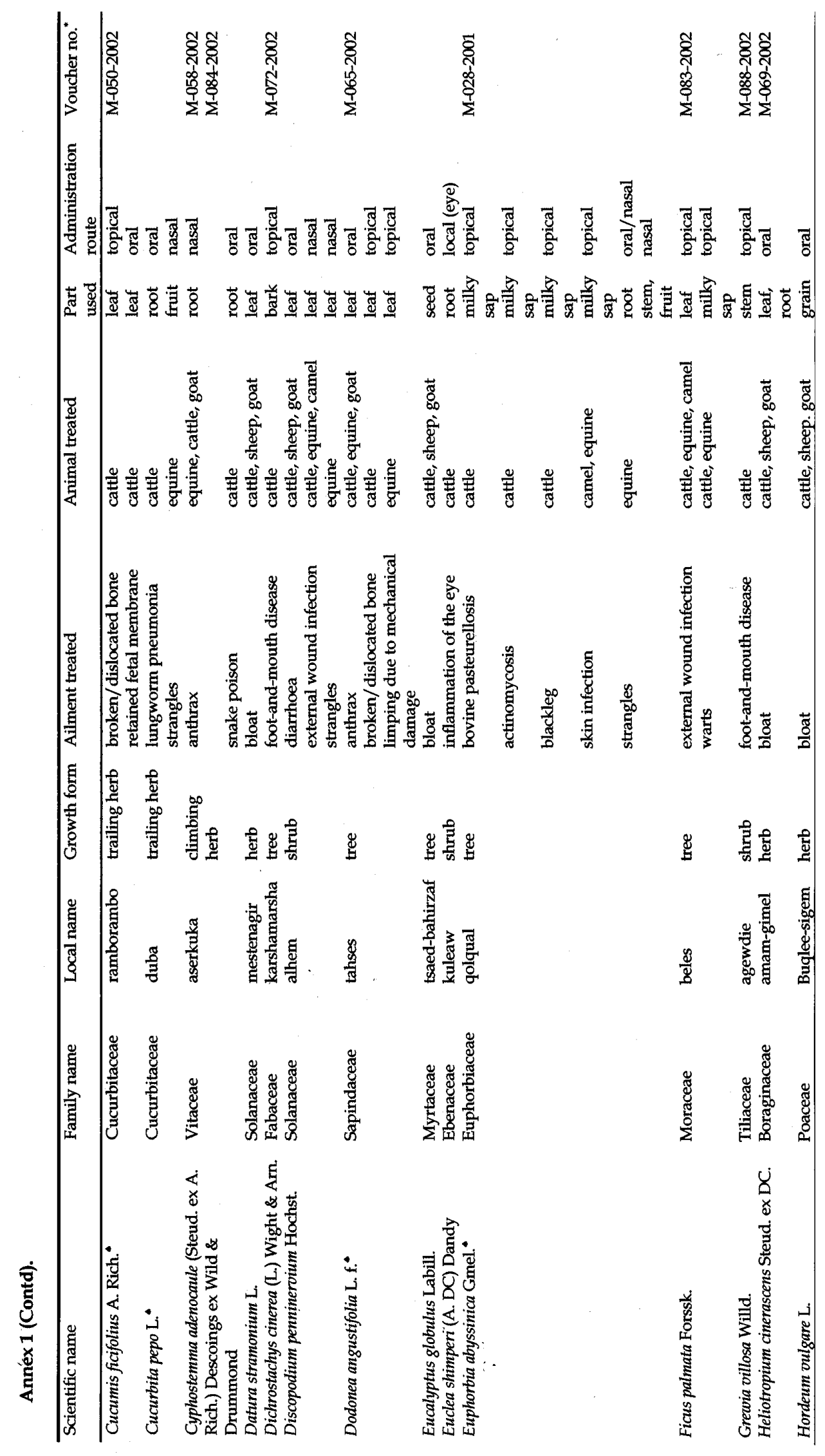




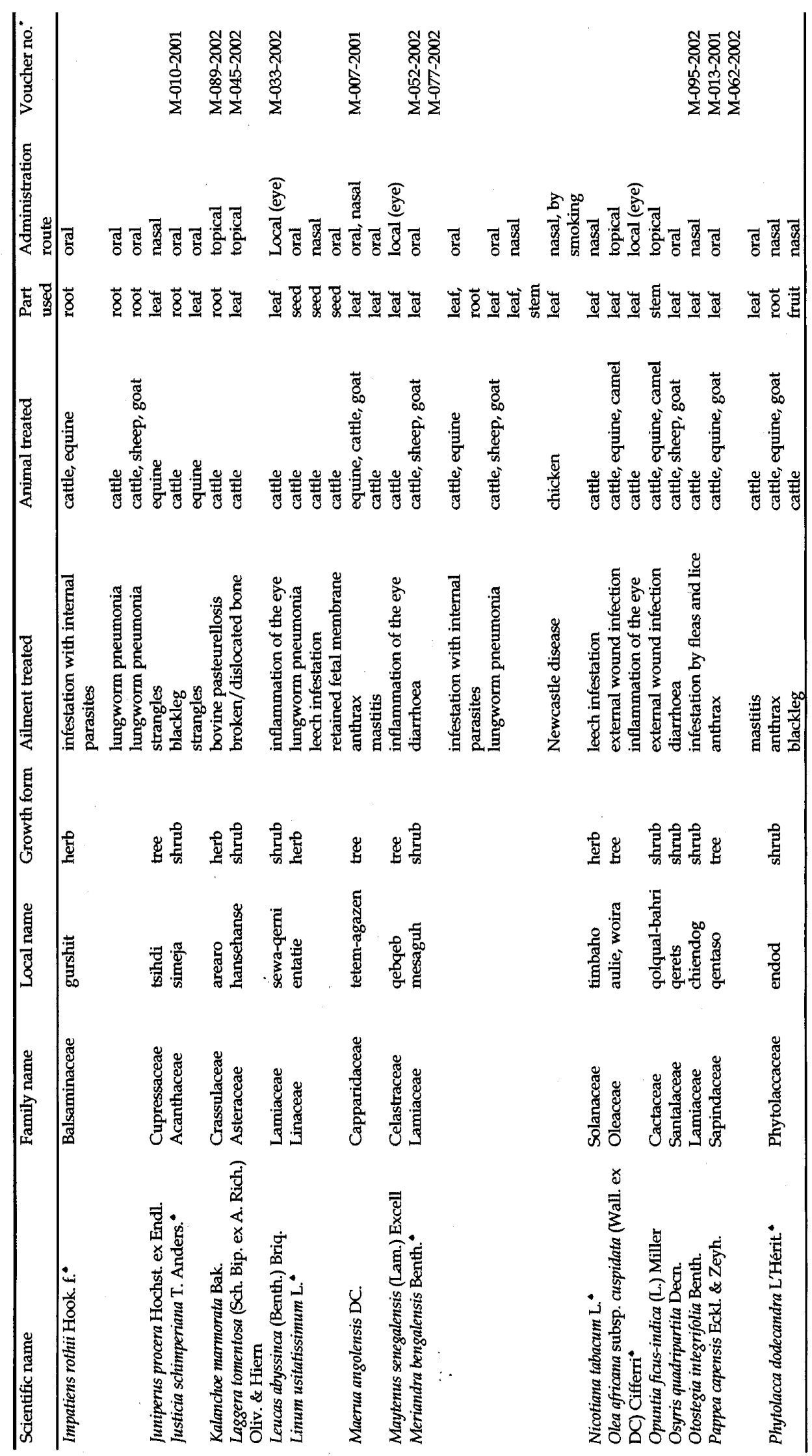




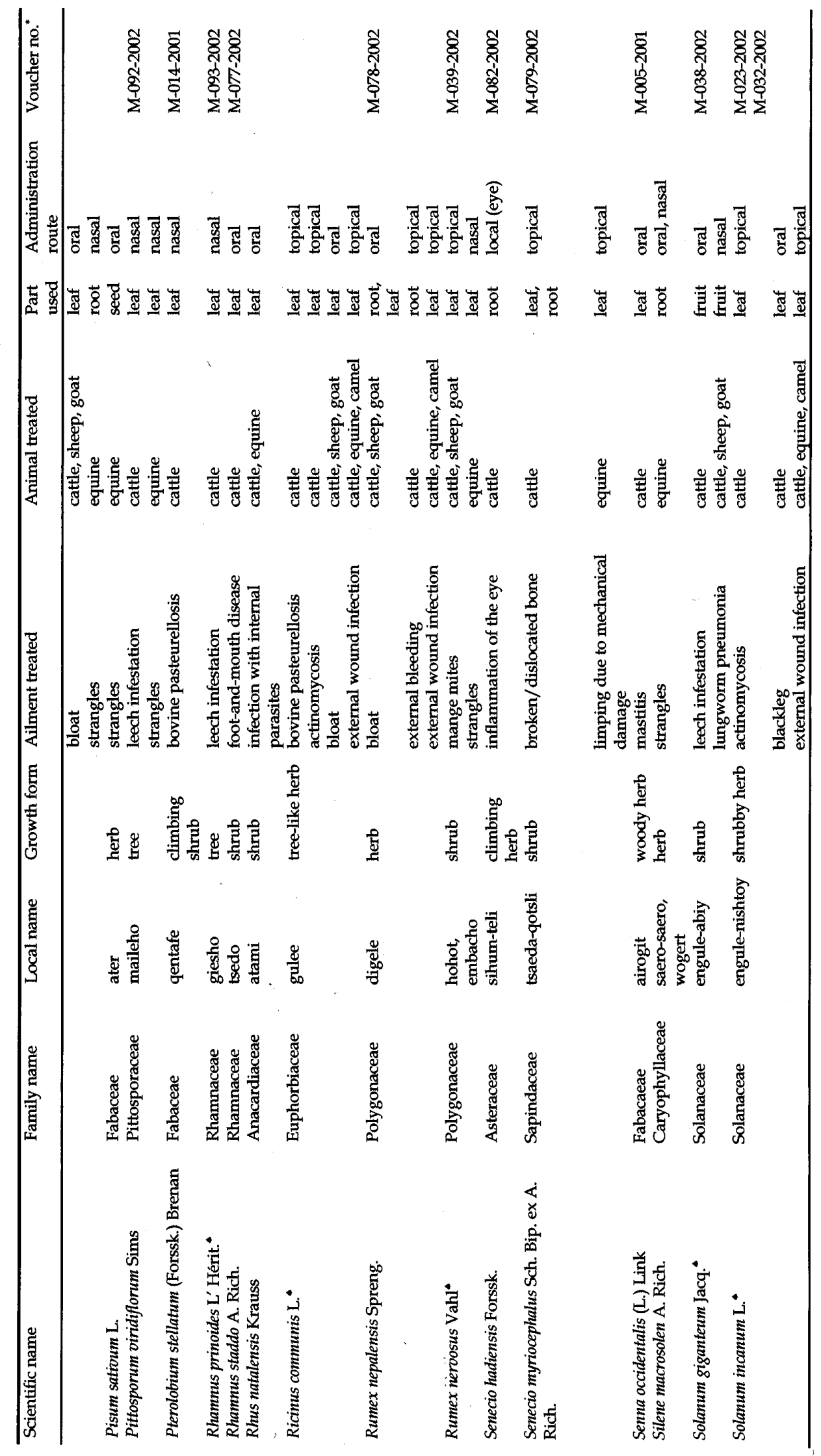




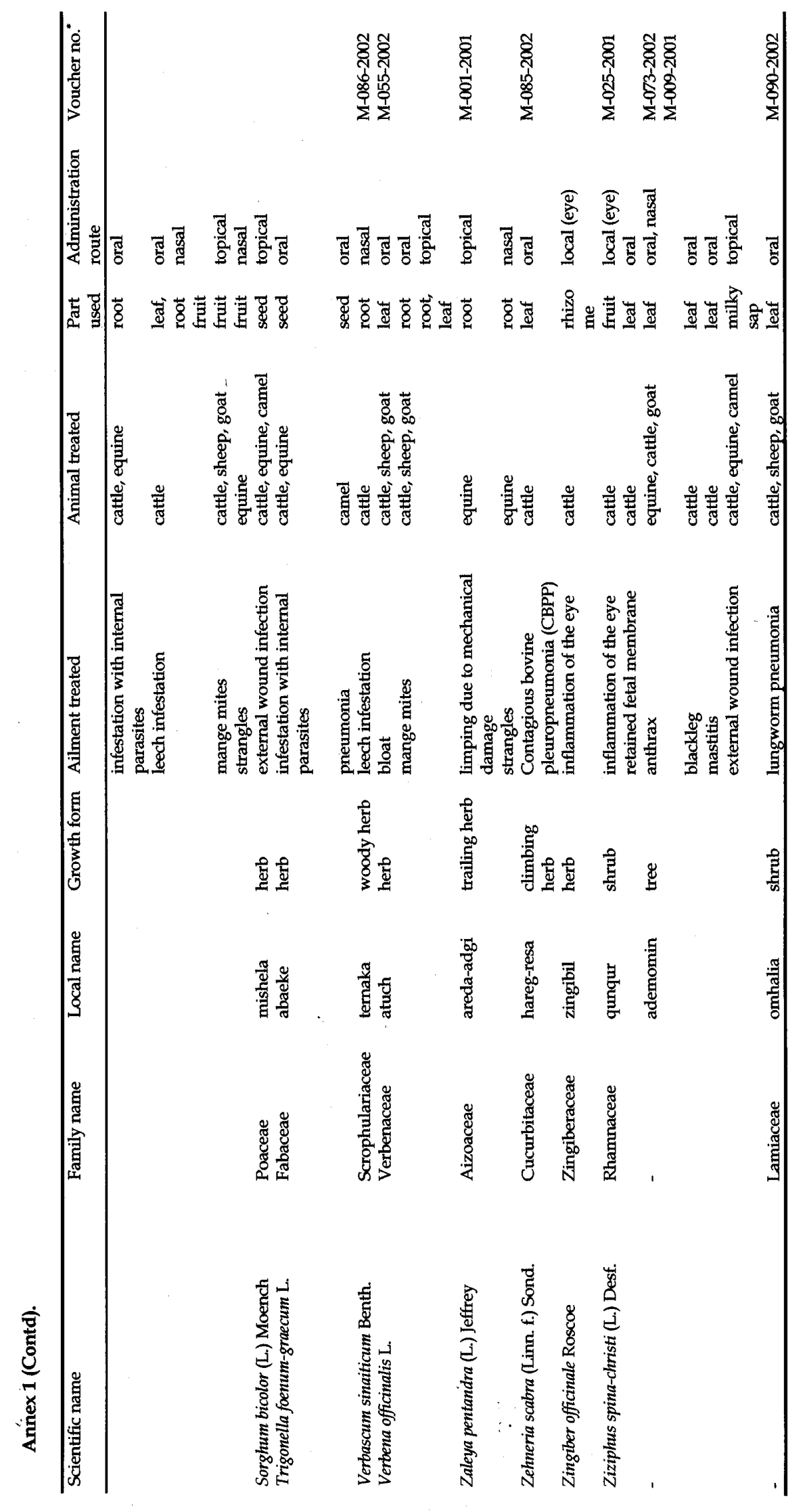

